\title{
Necessities, Properties, \& Merits of using Geopolymer Concrete
}

\author{
Manish Venugopal
}

\begin{abstract}
As urbanization across the globe is on the rise. Construction has become one of the largest industries across the world. Concrete being one of the most abundantly used material across the construction industry possess cement as the core ingredient in its mixture. Studies have indicated cement manufacturing alone accounts for about $8 \%$ of the carbon dioxide $\left(\mathrm{CO}_{2}\right)$ emissions across the world. With a forecast of $85 \%$ increase in the volume of construction by 2030, there is a need to protect the environment from being affected further by the emissions from the construction industry. As such there is an immediate need to resort to alternative materials to achieve environment friendly construction. One such material that has been in use for more than a decade is geopolymer concrete. This paper analysis the available literature for the necessity of geopolymer concrete to be used in the construction industry. In addition, it also explores the properties, and merits of using them towards a sustainable environment.
\end{abstract}

Keywords : Geopolymer Concrete, Necessities, Properties, Merits, Green Building, Construction Materials.

\section{INTRODUCTION}

G Global population is on the rise, it has increased from 1 billion in 1800 to 7.7 billion as of 2019 (Max Roser, 2020). Around 6 billion people lived near the cities as of 2001 (P. K. Mehta, 2002). Twentieth century experienced an enormous growth of energy, manufacturing, and transportation sectors due to population growth and urbanization (P. K. Mehta, 2002). Natural landscapes are transformed by humans in large proportions across the earth (Foley et al., 2005; Venugopal, 2019). Result of this continuous development has led to construction industry being one of the largest across the world. One of the major materials used in the construction industry is concrete. Concrete is second only to water in terms of global use (Rangan, 2014). Ordinary Portland cement is the material that is used as a binder in concrete mixture (Andrew, 2018).

(Rodgers, 2018) stated, globally 8\% of the carbon dioxide $\left(\mathrm{CO}_{2}\right)$ emission is from production of cement. With a forecast of $85 \%$ increase in the volume of construction by 2030 , there is a need to protect the environment from affected further

Revised Manuscript Received on February 27, 2020.

* Correspondence Author

Manish Venugopal, M.S. in Construction \& Facilities Management, Name of the affiliated College or University/Industry, City, Country. Email: mvenugo6997@gmail.com

(C) The Authors. Published by Blue Eyes Intelligence Engineering and Sciences Publication (BEIESP). This is an open access article under the CC BY-NC-ND license (http://creativecommons.org/licenses/by-nc-nd/4.0/) from the emissions from the industry (Max Roser, 2020). With the significant growth across the world the demand for cement is always on the rise. As such there is a significant need to reduce these emissions by using environmentally friendly green building materials such as geopolymer concrete.

\section{GEOPOLYMER CONCRETE}

Concrete mixture produced by the usage of a geopolymer as a binder instead of cement to produce is called as geopolymer concrete (Hardjito, Wallah, Sumajouw, \& Rangan, 2004) Geopolymer is created in an exothermic process. Inorganic polymeric amorphous mixture of aluminum and silicate is known as geopolymer (Institute, 2010; Van Chanh Bui \& Van Tuan, 2008). Binder is produced by a polymerization process involving an alkaline activating solution with sodium and aluminium (Aleem \& Arumairaj, 2012). It is a mixture of sodium and aluminium rich fly ash, sodium silicate and sodium hydroxide solution (Van Chanh Bui \& Van Tuan, 2008).

\section{METHODS}

The purpose of this study is to determine the necessities, properties, and merits of geopolymer concrete mixture instead of using ordinary Portland cement concrete mixture. The scope is achieved through analyzing the available literature on geopolymer concrete mixture. For the purpose of this study, more than 20 available literature from the previous decades on geopolymer concrete were analyzed.

\section{ANALYSIS}

\section{A. NECESSITIES OF GEOPOLYMER CONCRETE}

According to past studies, about 1.35 billion tons of cement is being produced annually, which accounts for about $\mathrm{CO}_{2}$ emissions of approximately 7\%. (Hardjito et al., 2004; Malhotra, 2002). By 2050, 4 billion tons of cement is expected to be produced annually (Schneider, Romer, Tschudin, \& Bolio, 2011). One ton of cement produces results in $900 \mathrm{~kg}$ of $\mathrm{CO}_{2}$ emission into the atmosphere (Benhelal, Zahedi, Shamsaei, \& Bahadori, 2013). (Rangan, 2014) stated that, major concerns on the environmental protection has raised due to increase in global warming and release of greenhouse gases such as carbon dioxide. Thermal energy is required in the production of cement. As such, the cement production consumes natural gas and fossil fuels in excessive amounts (Rahman, Rasul, Khan, \& Sharma, 2012). 
(Rahman et al., 2012) stated that, the raw materials and fossil fuels that is consumed in the cement production is extremely high and account for $20-25 \%$ of cement production cost. In addition, resistance to acids and sulfates is of concern for ordinary Portland cement despite being used in a large scale for infrastructure construction (Thokchom, Ghosh, \& Ghosh, 2009). Concrete structures designed to last for 50 years have deteriorated early within 20 to 30 years in corrosive environment (K. P. Mehta, 2001).

With environmental protection becoming significantly important across the globe, there is an immediate need to resort towards sustainable and green building materials such as geopolymer concrete.

\section{B. PROPERTIES OF GEOPOLYMER CONCRETE}

Extensive research have been conducted on the various properties of geopolymer concrete indicating the properties of geopolymer concrete. (Hardjito et al., 2004) stated that, compressive strength of geopolymer concrete depends on concentration of sodium hydroxide, curing time, and curing temperature. Increase in these factors resulted in increase in the compressive strength (Hardjito et al., 2004; Van Chanh Bui \& Van Tuan, 2008). For a similar mix of geopolymer concrete compared to an ordinary Portland cement concrete, the compressive strength rises by 1.5 times (Aleem \& Arumairaj, 2012). (Hardjito et al., 2004) stated that, there were no degradation in the compressive strength and any sign of setting of geopolymer concrete for 120 minutes. This indicates the superior workability of geopolymer concrete without any signs of reduction in the compressive strength. (Wallah, 2009) stated that, long term properties such as the drying shrinkage and creep of geopolymer concrete is very low compared to ordinary Portland cement concrete.

(Van Chanh Bui \& Van Tuan, 2008) stated that, geopolymer concrete is resistant against corrosion and suitable for tough environmental conditions involving acid and salt because of the absence of limestone. (Thokchom et al., 2009) performed an experimental analysis on geopolymer concrete by exposing them to sulfuric acid for 18 weeks. Results indicated they are highly resistant against them. Similarly (Song, Marosszeky, Brungs, \& Munn, 2005) stated that, geopolymer concrete has excellent durability by exposing them for 56 days to $10 \%$ sulfuric acid. Compared to ordinary Portland cement concrete, geopolymer concrete loses weight by $0.5 \%$ when it is exposed to $3 \%$ sulfuric acid (Al Bakri et al., 2012). (Rangan, 2014) conducted an experiment on geopolymer concrete by exposing them to $5 \%$ sulfate solution for a period of 1 year. Results indicated that they are highly resistant to sulfate attack.

\section{MERITS OF USING GEOPOLYMER CONCRETE}

Fly ash is by product of thermal power plants. Increase in power consumption produces more fly ash (Van Chanh Bui \& Van Tuan, 2008). (Aleem \& Arumairaj, 2012) stated that, geopolymer concrete can be used in precast industries. No landfills will be required for dumping of fly ash, since it is being used in producing the geopolymer concrete. Therefore, using fly ash in geopolymer concrete is environmentally friendly. (Rangan, 2014) stated that, as geopolymer concrete are resistant to sulphate attacks. Results of which eliminates expansion, spalling, and cracking of concrete which are present in ordinary Portland cement concrete. (Van Chanh
Bui \& Van Tuan, 2008) stated that, geopolymer concrete is resistant against corrosion and suitable for tough environmental conditions involving acid and salt because of the absence of limestone. (Al Bakri et al., 2012) stated that, geopolymer concrete can be used for marine construction due to its resistance against aggressive environment.

\section{RESULTS}

From the analysis performed on the past literature available, these results were derived.

- Geopolymer concrete has a higher compressive strength (Aleem \& Arumairaj, 2012) \& durability (Song, Marosszeky, Brungs, \& Munn, 2005) compared to the ordinary Portland cement concrete.

- In comparison to ordinary Portland cement concrete, geopolymer concrete has a higher resistance to acid and aggressive environment (Van Chanh Bui \& Van Tuan, 2008).

- Geopolymer concrete has a higher sulfate resistance compared to ordinary Portland cement concrete (Thokchom et al., 2009).

\section{CONCLUSION}

Geopolymer concrete has been studied for more than a decade now. Tons of research have been carried out globally to show the merits of this sustainable material instead of the ordinary Portland cement. Research indicates geopolymer concrete to be a potential material to replace the ordinary Portland cement concrete. Current knowledge from past studies show that, the strength and durability of geopolymer concrete is higher compared to the ordinary Portland cement concrete. In addition, it also shows that Geopolymer concrete tends to be more resistant to acid and aggressive environment compared to Portland cement concrete.

The usage of geopolymer concrete will lead to a reduction in the production of ordinary Portland cement concrete. Result of which will be a decrease in carbon dioxide emissions into the atmosphere. Geopolymer concrete is produced with the help of fly ash which is a waste or by product material from the steel industry. Therefore, resulting in reducing and recycling the fly ash produced which tends to be beneficial for the environment. In addition, geopolymer concrete has good corrosion resistance, drying shrinkage and creep which will aid in constructing sustainable long-lasting structures.

\section{REFERENCES}

1. Al Bakri, A. M., Kamarudin, H., Bnhussain, M., Nizar, I. K., Rafiza, A. \& Zarina, Y. (2012). The processing, characterization, and properties of fly ash based geopolymer concrete. Rev. Adv. Mater. Sci, 30(1), 90-97.

2. Aleem, M. A., \& Arumairaj, P. (2012). Geopolymer concrete-a review. International journal of engineering sciences \& emerging technologies, $1(2), 118-122$.

3. Andrew, R. M. (2018). Global CO 2 emissions from cement production. Earth System Science Data, 10(1), 195.

4. Benhelal, E., Zahedi, G., Shamsaei, E., \& Bahadori, A. (2013). Global strategies and potentials to curb CO2 emissions in cement industry. Journal of cleaner production, 51, 142-161.

5. Foley, J. A., DeFries, R., Asner, G. P., Barford, C., Bonan, G., Carpenter, S. R., . . . Gibbs, H. K. (2005). Global consequences of land use. science, 309(5734), 570-574. 
6. Hardjito, D., Wallah, S. E., Sumajouw, D. M., \& Rangan, B. V. (2004) On the development of fly ash-based geopolymer concrete. Materials Journal, 101(6), 467-472.

7. Institute, G. (2010). What Is a Geopolymer? Introduction. Retrieved from http://www.geopolymer.org/science/introduction/

8. Malhotra, V. (2002). Introduction: sustainable development and concrete technology. Concrete international, 24(7).

9. Max Roser, H. R. a. E. O.-O. (2020). World Population Growth. Retrieved from https://ourworldindata.org/world-population-growth

10. Mehta, K. P. (2001). Reducing the environmental impact of concrete. Concrete international, 23(10), 61-66.

11. Mehta, P. K. (2002). Greening of the concrete industry for sustainable development. Concrete international, 24(7), 23-28.

12. Rahman, A., Rasul, M., Khan, M. M. K., \& Sharma, S. (2012). Industrial waste as alternative fuel in cement industry: Its impact on environment. Paper presented at the Proceedings of the 7th WSEAS International Conference on Energy \& Environment: Recent researches in environmental and geological science.

13. Rangan, B. V. (2014). Geopolymer concrete for environmental protection. The Indian Concrete Journal, 88(4), 41-59.

14. Rodgers, L. (2018). Climate change: The massive CO2 emitter you may not know about. Retrieved from https://www.bbc.com/news/science-environment-46455844

15. Schneider, M., Romer, M., Tschudin, M., \& Bolio, H. (2011) Sustainable cement production-present and future. Cement and concrete research, 41(7), 642-650.

16. Song, X., Marosszeky, M., Brungs, M., \& Munn, R. (2005). Durability of fly ash based geopolymer concrete against sulphuric acid attack. Paper presented at the International Conference on Durability of Building Materials and Components.

17. Thokchom, S., Ghosh, P., \& Ghosh, S. (2009). Resistance of fly ash based geopolymer mortars in sulfuric acid. ARPN J. Eng. Appl. Sci, 4(1), 65-70.

18. Van Chanh Bui, D. T., \& Van Tuan, D. (2008). Recent research geopolymer concrete-Nguyen during the 3rd ACF Int. Conf. ACF/VCA.

19. Venugopal, M. (2019). Evaluating Pollutant Concentrations in Urban Streams Based on Precipitation, Network of Stormwater BMPs, and Impervious Cover. The University of North Carolina at Charlotte.

20. Wallah, S. E. (2009). Drying shrinkage of heat-cured fly ash-based geopolymer concrete. Modern Applied Science, 3(12), 14-21.

\section{AUTHORS PROFILE}

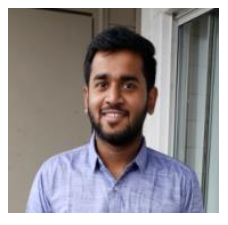

Manish Venugopal, is a recent graduate with a Master of Science in construction \& facilities management (2019) from University of North Carolina at Charlotte, North Carolina. Engineering. He also possesses a bachelor's in civil engineering from Sri Sivasubramaniya Nadar College of Engineering affiliated to Anna University, India. 